SUBJECT AREAS:

UBIQUITINS

PROTEIN QUALITY CONTROL

UBIQUITYLATION

DRUG DEVELOPMENT

Received

19 February 2013

Accepted

4 June 2013

Published

11 September 2013

Correspondence and requests for materials should be addressed to Y.J.Y. (yiyoo@gist.ac. \section{knockdown of polyubiquitin gene Ubb as potential cancer therapeutic intervention}

\author{
Choongseob Oh', Soonyong Park' , Eun Kyung Lee ${ }^{2} \&$ Yung Joon Yoo'
}

\begin{abstract}
${ }^{1}$ School of Life Sciences, Gwangiu Institute of Science \& Technology (GIST), Gwangju 500-712, Republic of Korea, ${ }^{2}$ Deaprtment of Biochemistry, College of Medicine, The Catholic University of Korea, Seoul 137-701, South Korea.
\end{abstract}

Ubiquitin is involved in almost every cellular process, and it is also known to be a stress-inducible protein. Based on previous reports that many types of cancer display an elevated level of ubiquitin, we hypothesized that this increased amount of ubiquitin is essential for the growth of cancer cells and that, consequently, the downregulation of ubiquitin may be a potential anti-cancer treatment. We first found that the level of ubiquitin can be effectively downregulated via knockdown of a polyubiquitin gene, $U b b$, with siRNA $(U b b-\mathrm{KD})$ and then demonstrated its anti-cancer effects in several cancer cell lines and xenograft mice. $U b b$-KD resulted in the attenuation of TNF $\alpha$-induced NF- $\mathrm{KB}$ activation, the stabilization of the tumor suppressor p53, and stress-sensitization. Taken together, downregulation of ubiquitin through $U b b-\mathrm{KD}$ is a potential anti-cancer treatment by inhibiting ubiquitination at multiple sites related to oncogenic pathways and by weakening the ability of cancer cells to overcome increased stress.

biquitin (Ub) is a small eukaryotic protein that is covalently attached to proteins by the consecutive actions of three distinct enzymes ${ }^{1,2}$. Ub is first activated by a Ub-activating enzyme (E1), transferred to a Ubconjugating enzyme (E2), and then attached to a target protein under the control of a Ub ligase (E3). There are only a few E1 enzymes, $\sim 30 \mathrm{E} 2 \mathrm{~s}$, and over $600 \mathrm{E} 3 \mathrm{~s}$ in humans, which together generate a variety of different ubiquitinated forms of many thousands of proteins by single or multiple site monoubiquitination as well as by polyubiquitinations of different lengths and topologies ${ }^{3,4}$. A variety of ubiquitinated products are then specifically recognized either by Ub receptors containing Ub-binding domains (UBD), leading to downstream effects ${ }^{5,6}$, or by deubiquitinating enzymes, which catalyze the reverse reaction ${ }^{7}$. Thus, the Ub system is extremely versatile and can play multiple essential roles in various cellular processes by regulating not only protein stability but also protein interactions, trafficking, and activation.

Therefore, it is not surprising that alterations in the Ub system have been observed in many types of human cancers and that many of its components, when deregulated, have been found to play key roles in cellular processes relevant to tumorigenesis ${ }^{8,9}$. Due to, in part, the success of the proteasome inhibitor bortezomib, the various upstream components of the Ub system are currently under investigation or in clinical study for the development of new anti-cancer therapies. These studies now encompass almost every step of the Ub system, including not only the proteasome but also E1-E2-E3 cascade enzymes, Ub receptors, and deubiquitinating enzymes ${ }^{9-13}$.

We are particularly interested in the elevated level of $\mathrm{Ub}$ that has been observed in most, if not all, cancer cells ${ }^{14-18}$. In addition, a positive relationship between Ub levels and the progression of hepatocellular carcinoma has been reported ${ }^{19}$. Ub exists in cells either free or covalently conjugated to various intracellular proteins. Free Ub must be provided in a timely manner and in an adequate amount for conjugation to a variety of proteins; it is either continuously supplied for housekeeping functions, such as protein homeostasis, including the removal of misfolded or damaged proteins ${ }^{1,20}$, or transiently supplied for signaling pathways upon a signaling cue, such as the $\mathrm{TNF} \alpha$-activated NF- $\kappa \mathrm{B}$ pathway ${ }^{21}$. Therefore, elevated Ub levels in cancer cells imply that the housekeeping function is overactive and/or that certain ubiquitination-mediated signaling pathways are chronically hyperactive. In addition, given that cancers exhibit various stress phenotypes, including proteotoxic stress ${ }^{22,23}$, and that Ub itself is a stress-inducible protein ${ }^{24,25}$, increased $\mathrm{Ub}$ is likely to support the ability of cancer cells to overcome escalating cellular stresses.

In this study, we hypothesized that an elevated Ub level during tumorigenesis becomes essential and is maintained for the survival and proliferation of the cancer cells; thus, the downregulation of Ub levels would 
be preferentially detrimental to cancer cells. Here, we demonstrated that Ub levels are efficiently reduced by knockdown of the polyUb gene $U b b(U b b-\mathrm{KD})$ with small interfering RNA (siRNA), which effectively inhibited the survival and proliferation of cancer cells. Although the detailed molecular mechanism is not clear, we identified multiple potential mechanisms for the anti-cancer effects induced by limiting the supply of $\mathrm{Ub}$ via $U b b-\mathrm{KD}$, including delay of NF- $\kappa \mathrm{B}$ activation, inhibition of cell cycle progression, and stabilization of the tumor suppressor p53. Taken together, our data strongly suggest that the downregulation of $\mathrm{Ub}$ by $\mathrm{Ubb}-\mathrm{KD}$ has potential as a new therapeutic intervention for cancer treatment.

\section{Results}

Downregulation of Ub by knockdown of the polyUb gene $U \boldsymbol{b b}$. First, we attempted to downregulate the level of Ub by blocking the de novo synthesis of Ub. Four different genes encode $\mathrm{Ub}$ in humans: Rps27a, Uba52, Ubb, and Ubc (Fig. 1a). Among them, the polyUb genes $U b b$ and $U b c$, which encode 3 and 9 tandem Ubs, respectively, were targeted for knockdown. $U b b$ and $U b c$ were chosen because $R p s 27 a$ and Uba52 are thought to be essential for protein synthesis because they encode fusion proteins of $\mathrm{Ub}$ with the ribosomal subunits of S27a and L40, respectively. When $20 \mathrm{nM}$ of siRNA targeting the mRNA from the $U b b$ gene ( $U b b$ siRNA) was transfected into SH-SY5Y human neuroblastoma cells, Ubb mRNA was almost completely degraded in $48 \mathrm{~h}$, while the expression of other Ub genes was not affected (Fig. 1b). Specific degradation of $U b b$ mRNA by the treatment of $U b b$ siRNA was further confirmed by quantitative real-time PCR (Supplementary Fig. 1). By contrast, transfection with siRNA against $U b c$ mRNA resulted in incomplete degradation of $U b c$ mRNA and substantial degradation of Rps27a mRNA (data not shown). In cells, Ub is either free or covalently conjugated to many different intracellular proteins. When the Ub level was assessed by anti-Ub immunoblot after SDS-PAGE, both mono-Ub and conjugated Ub levels decreased in a dose-dependent manner upon treatment with $5 \mathrm{nM}, 10 \mathrm{nM}$ and $20 \mathrm{nM} \mathrm{Ubb}$ siRNA (Fig. 1c). Because mono-Ub and conjugated Ub cannot be quantitatively compared in an anti-Ub immunoblot, we independently compared each amount by densitometry and found that mono-Ub showed a larger decrease (Fig. 1d). For example, Ubb-KD with $20 \mathrm{nM} U b b$ siRNA resulted in a greater than $70 \%$ decrease in the mono-Ub level, whereas there was less than a $30 \%$ decrease in the level of conjugated Ub (Fig. 1d). a

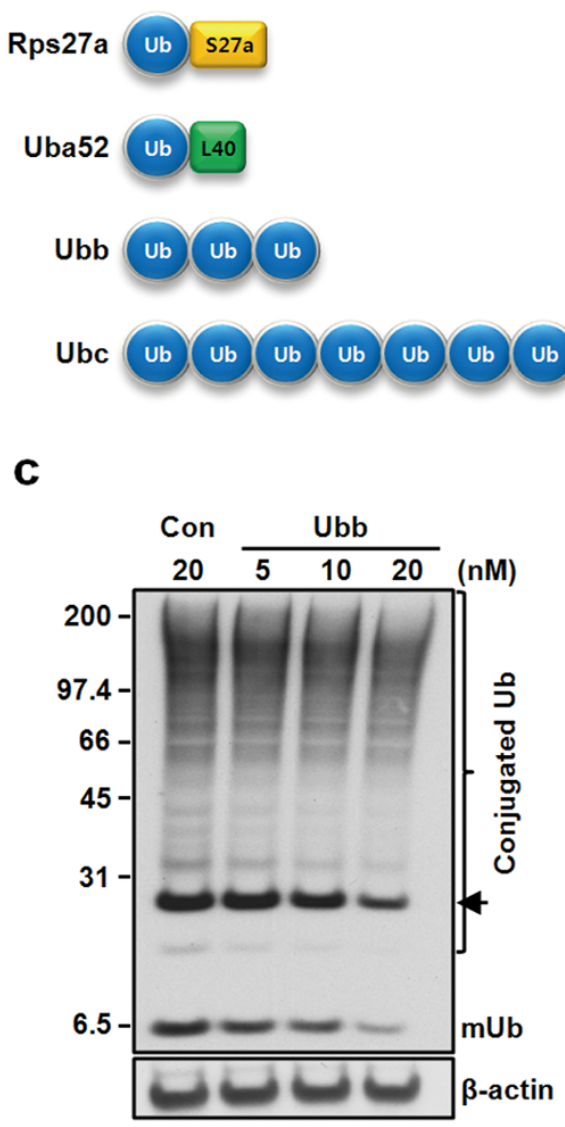

b

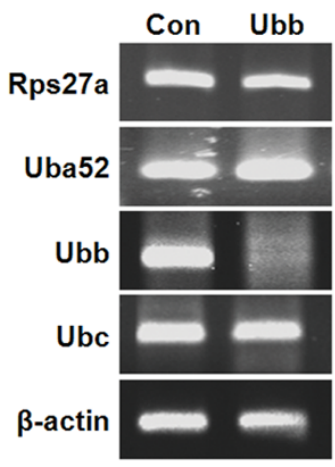

d

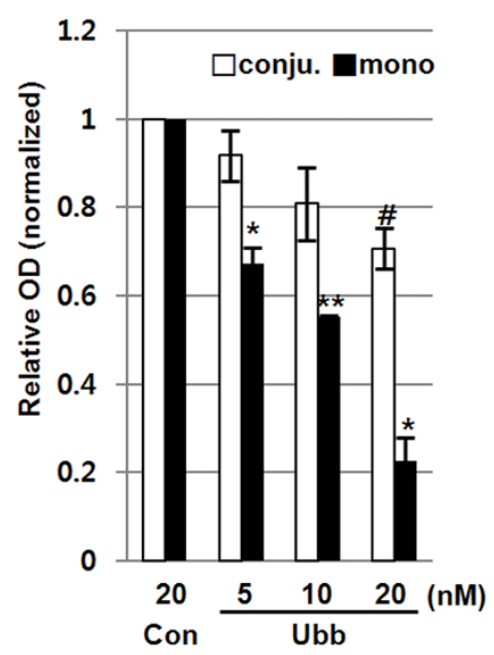

Figure $1 \mid$ Ub levels are downregulated by the knockdown of $U \boldsymbol{b b}$ mRNA with siRNA. (a) Schematic representation of the 4 Ub genes; Rps27a and $U b a 52$ encode $\mathrm{Ub}$ as a fusion protein with the ribosomal subunits S27a and L40, respectively, whereas $U b b$ and $U b c$ encode tandem units of Ub with 3 and 9 repeats, respectively. All Ub gene products are known to be processed co-translationally. (b) SH-SY5Y neuroblastoma cells were transfected with 20 nM control siRNA or $U b b$ siRNA for $48 \mathrm{~h}$, and the mRNA level of each Ub gene was analyzed by PCR. Ubb siRNA effectively and specifically depleted $U b b$ mRNA. $\beta$-actin mRNA was used as a control. (c) SH-SY5Y cells were transfected with different concentrations of $U b b$ siRNA ( 5,10 , and $20 \mathrm{nM}$ ) for $48 \mathrm{~h}$, and the Ub level was analyzed by Western blotting following SDS-PAGE of whole protein extracts. A mono-Ub (mUb) can be resolved from conjugated Ubs appeared as smear and several discrete bands including ubiquitinated histone (arrow). (d) The amounts of mono-Ub and conjugated Ub were independently compared by densitometry $(n=2)$. Both decreased in a dose-dependent manner, but the downregulation of mono-Ub was particularly noticeable. The data are shown as the mean \pm SD, \#, $\mathrm{p}<0.1 ;{ }^{*}, \mathrm{p}<0.05 ;{ }^{* *}, \mathrm{p}<0.01$. 
Mono-Ub under reducing conditions includes not only free mono-Ub but also Ub thioester linked to enzymes, which can be separated by NR/R-2DE. During NR/R-2DE, the thioester bonds (denoted by $\sim$ ) are maintained under non-reducing conditions in the first dimensional separation but are easily cleaved under the reducing conditions of the second dimensional separation, so that thioester-linked Ubs are detached from enzymes and migrate independently. In addition to free mono- $\mathrm{Ub}$, a total of 5 discrete monoUb spots were detected by anti-Ub immunoblotting after NR/R-2DE: one spot from E1 $\sim \mathrm{Ub}$ and 4 spots from E2 $\sim \mathrm{Ub}$ (Supplementary Fig. 2). Densitometric analyses of these mono-Ub spots from HEK293 cells treated with $10 \mathrm{nM}$ control siRNA or $U b b$ siRNA revealed that free mono-Ub and all 5 mono-Ub spots originated from thioesterlinked Ub, were decreased by approximately 50\% (Supplementary Figs. $2 \mathrm{~b}$ and $2 \mathrm{c}$ ). Consistent with these results, the amount of Ub-linked enzyme, for example, Ube2K/UBE $2 \mathrm{~K} \sim \mathrm{Ub}$, was similarly reduced by treatment with $U b b$ siRNA (Supplementary Fig. 2d). Thus, the downregulation of de novo Ub synthesis by Ubb siRNA decreased the amount of free mono- $\mathrm{Ub}$ and, in turn, the level of Ubcharged enzymes, thereby resulting in a reduced supply of $\mathrm{Ub}$ for conjugation.

$U b b$-KD inhibits cell proliferation and induces apoptotic cell death in cultured cancer cells. We next investigated whether $U b b$ $\mathrm{KD}$ could inhibit cell proliferation as expected. When SH-SY5Y cells were transfected with $20 \mathrm{nM} U b b$ siRNA and cultured for $72 \mathrm{~h}$, inhibition of cell proliferation was clearly observed by light microscopy (upper panel in Fig. 2a). MTT assays demonstrated that cell proliferation was inhibited by $55 \% \pm 20 \%$ in $U b b$ siRNAtransfected cells compared with control siRNA-transfected cells (upper panel in Fig. 2b). We also observed that many Ubb siRNAtransfected cells displayed a shrunken shape and detached from the culture plates, suggestive of apoptotic cell death. FACS analyses revealed that $70 \% \pm 16 \%$ of $U b b$ siRNA-transfected cells were apoptotic cells in the sub-G1 population, whereas only $10 \% \pm$ $0.9 \%$ of control siRNA-transfected cells were apoptotic (upper panel in Fig. 2c). This difference in apoptotic cell death was also confirmed by the increased cleavage of PARP in Ubb siRNAtreated cells (Fig. 2c).

The effects of $U b b$-KD on cancer cell proliferation and apoptosis were further examined in PC3 prostate cancer cells and HepG2 hepatocellular carcinoma cells. At $72 \mathrm{~h}$ after transfection with $20 \mathrm{nM} \mathrm{Ubb}$ siRNA, cell proliferation was inhibited by $70 \% \pm 8 \%$ in PC3 cells and by $45 \% \pm 20 \%$ in HepG 2 cells (Figs. $2 \mathrm{a}$ and $2 \mathrm{~b}$ ). This treatment also induced apoptotic cell death at $72 \mathrm{~h}$ in $43 \% \pm 10 \%$ of PC3 cells and $57 \% \pm 10 \%$ of HepG2 cells (Fig. 2 c). Increased cleavage of PARP was also observed in both $U b b$ siRNA-treated cell lines (Fig. 2c). In addition to MTT assay, we assessed the effect of $U b b$-KD on colony forming ability for 7 days by clonogenic assays and found that the colony forming ability was reduced by the treatment of $20 \mathrm{nM} \mathrm{Ubb}$ siRNA to $66.7 \% \pm 6 \%, 34.7 \% \pm 3 \%$, and $47 \pm 20 \%$ for SH-SY5Y, PC3, and HepG2 cells, respectively (Supplementary Fig. 3).

Because $U b b$-KD induced apoptotic cell death, we also examined its effect on cell cycle progression. SH-SY5Y, PC3, and HepG2 cells were transfected with control siRNA or $U b b$ siRNA, and cell cycle distributions were analyzed at $0 \mathrm{~h}, 12 \mathrm{~h}, 24 \mathrm{~h}, 36 \mathrm{~h}$, and $48 \mathrm{~h}$ by FACS (Fig. 2d). In SH-SY5Y cells, apoptotic cell death was detected at $48 \mathrm{~h}$ without any noticeable G2/M arrest (Fig. $2 \mathrm{~d}$ ). By contrast, the cell population at $\mathrm{G} 2 / \mathrm{M}$ phase began increasing before apoptotic cells appeared in PC3 and HepG2 cells (Fig. 2d). Therefore, sequential induction of G2/M arrest and apoptosis after $U b b$-KD appears to be cell-type dependent in both PC3 and HepG2 cells but not in SHSY5Y cells.

Given that PARP cleavage increased upon the downregulation of Ub by $U b b-\mathrm{KD}$, we tested $20 \mu \mathrm{MzVAD}$-fmk on those cells and found that the observed cell death was prevented by a caspase inhibitor almost completely in SH-SY5Y and HepG2 cells and partially in PC3 cells (Supplementary Fig. 4), implying that cell death by $U b b$ $\mathrm{KD}$ was dependent on caspases.

Taken all together, the downregulation of $\mathrm{Ub}$ level by $U b b-\mathrm{KD}$ effectively inhibited the cell proliferation and induced apoptotic cell death in cancer cells although the efficiency of $U b b$-KD and the rate of cell death seemed to be dependent on cancer cell types.

$U b b$-KD is preferentially cytotoxic to MCF7 cancer cells than MCF10A normal cells. Interestingly, $U b b-K D$ inhibited the proliferation of MCF7 breast cancer cells to a much greater extent than MCF10A normal breast cells: $38 \% \pm 7 \%$ in MCF7 cells compared with $12 \% \pm 2 \%$ in MCF10A cells (Figs. $3 \mathrm{a}$ and $3 \mathrm{~b}$ ). In addition, $U b b$-KD induced increased apoptotic cell death in MCF7 cells compared to MCF10A cells: $31 \% \pm 3 \%$ in MCF7 cells compared with $5.6 \% \pm 4.9 \%$ in MCF10A cells. Differences in apoptotic cell death were also confirmed by an increased level of cleaved PARP and DNA fragmentation in Ubb siRNA-transfected MCF7 cells compared with MCF10A cells (Figs. 3c and 3d). Our results clearly demonstrated that the downregulation of $\mathrm{Ub}$ by $U b b-\mathrm{KD}$ is preferentially more cytotoxic to MCF7 cancer cells than MCF10A normal cells. We further evaluated $U b b-\mathrm{KD}$ on the proliferation of another normal cell. When Detroit 551 normal human embryonic skin cells were transfected with $20 \mathrm{nM} U b b$ siRNA, Ub level was significantly downregulated but there was little effects on cell proliferation (Supplementary Fig. 5), supporting our hypothesis that cancer cells are more reliant on the Ub level than normal cells.

$\boldsymbol{U} \boldsymbol{b} \boldsymbol{b}$-KD inhibits tumor cell growth in a mouse xenograft model. We further examined the inhibitory effect of $U b b$-KD on tumor cell growth in a mouse xenograft model. For this purpose, PC3 cells were first transfected with either control siRNA or $U b b$ siRNA and then injected subcutaneously into the left and right flanks of nude mice (n $=11$ ). Tumor size was measured every 5 days after injection, and the final tumor mass was weighed on day 40 (Fig. 4). PC3 cell-derived tumor growth was partially blocked by $U b b-\mathrm{KD}$, resulting in an approximately $40 \%$ reduction in both tumor volume and weight (Fig. 4). Given that we employed siRNA to downregulate the Ub level of injecting PC3 cells, Ub level was presumably resumed at the relatively early stage of tumor growth so that $40 \%$ reduction in tumor size should be attributed to the initial effect of Ub depletion. Therefore, it was not surprised to observe no difference in Ub level between left and right tumors at day 40 (Supplementary Figs. 6a and $6 b)$. However, reduced Ub level could be observed at least in day 5 tumors derived from PC3 cells with $U b b-\mathrm{KD}$ compared with the control (Supplementary Figs. 6c and 6d).

$\boldsymbol{U} \boldsymbol{b} \boldsymbol{b}$-KD inhibits Ub-dependent protein degradation. To assess the effect of $U b b-\mathrm{KD}$ on protein degradation, we first analyzed the stability of unstable GFP (GFPu), a test substrate protein for ubiquitination-dependent proteasomal degradation ${ }^{26}$, using $\mathrm{SH}-$ SY5Y cells stably expressing GFPu, and found that $U b b$-KD clearly stabilized GFPu in cells (Fig. 5a). We also analyzed the endogenous cellular proteins and found that the p53 tumor suppressor, a known ubiquitination-dependent proteasomal substrate, was stabilized in $U b b$ siRNA-transfected cells, whereas ornithine decarboxylase (ODC), a known ubiquitination-independent proteasomal substrate, was not stabilized in the same cells (Fig. 5b). In addition, the $\alpha$-chain of the T-cell receptor ( $\alpha \mathrm{TCR}$ ), an endoplasmic reticulum-associated degradation (ERAD) substrate, was also stabilized in $\alpha$ TCR-expressing HeLa cells after transfection with $U b b$ siRNA (Fig. 5c). Taken together, the reduction in $\mathrm{Ub}$ levels by $U b b$-KD effectively inhibits ubiquitination-dependent proteasomal degradation, presumably via the attenuation of ubiquitination process.

Given that ubiquitination is also involved in the endocytosis and lysosomal degradation of many receptors ${ }^{27}$, we examined the stability of EGFR in $U b b$ siRNA-transfected HeLa cells after treatment with 
a
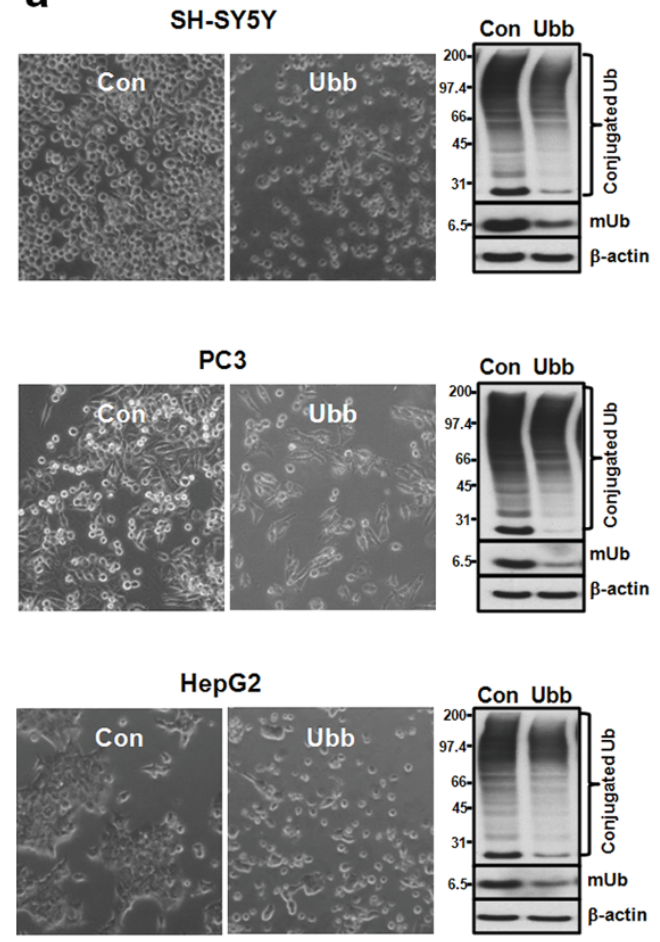

b
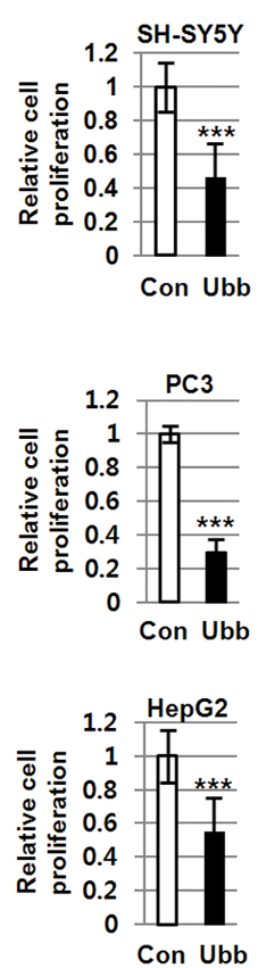

C
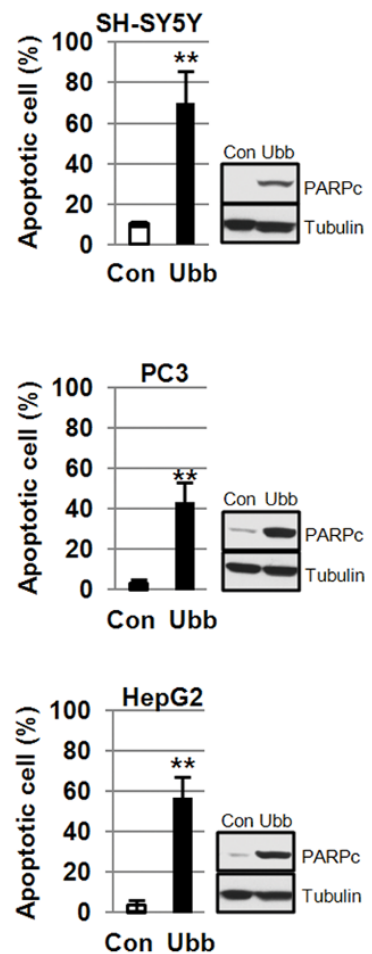

d
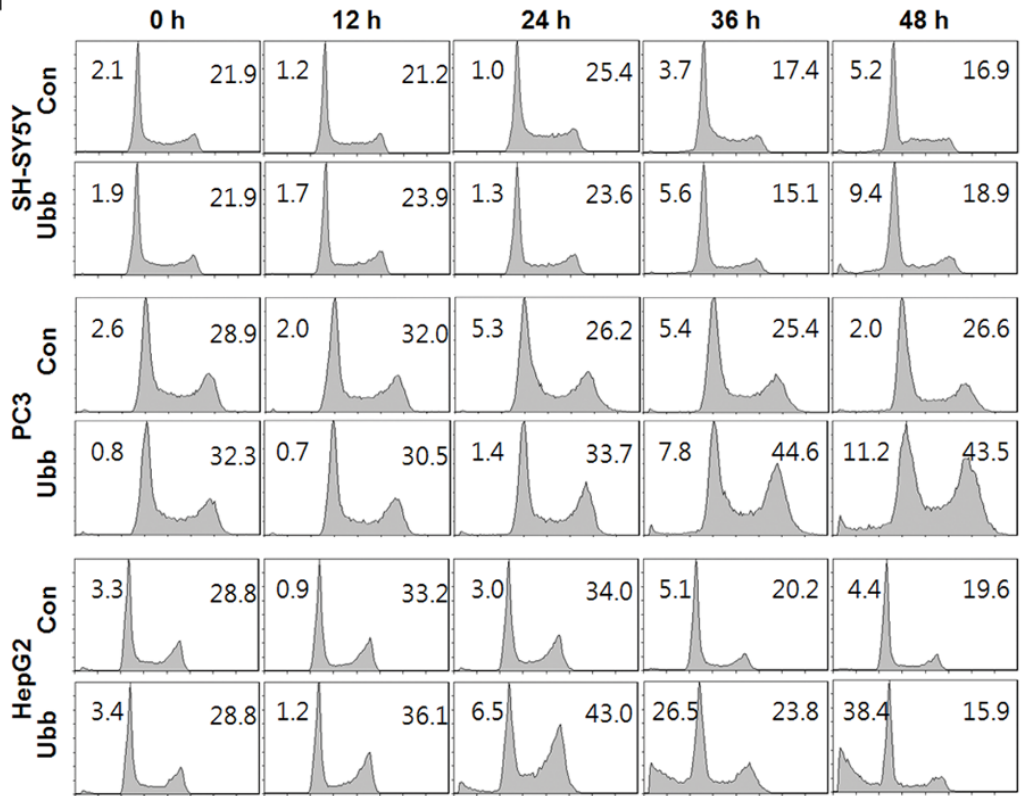

Figure $2 \mid U \boldsymbol{b} b$-KD inhibits cell proliferation and induces apoptotic cell death. (a) SH-SY5Y cells, PC3 cells, and HepG2 cells were transfected with $20 \mathrm{nM}$ control siRNA or $U b b$ siRNA for $72 \mathrm{~h}$ and observed by light microscopy. The levels of Ub in siRNA-transfected cells were compared by Western blot. $\beta$-actin was used as a control. (b) Relative cell proliferation of siRNA-transfected cells was measured by MTT assay $(\mathrm{n}=9$ ). (c) Apoptotic cells at $72 \mathrm{~h}$ were assessed by measuring the sub-G1 population by FACS analysis $(\mathrm{n}=2)$. Cleaved PARP cleavage was monitored as an apoptotic product by Western blot. Tubulin was used as a control. (d) The cell cycle distribution of the siRNA-transfected cells was analyzed at the indicated time by FACS. The 2 values in each panel indicate the percentage of cells at sub-G1 and G2/M stages. The data are shown as the mean $\pm \mathrm{SD}, * *, \mathrm{p}<0.01$; ***, $\mathrm{p}<0.001$.

EGF. Degradation of the EGFR was significantly delayed by $U b b$ $\mathrm{KD}$, with an increase in the estimated half-life of EGFR from $30 \mathrm{~min}$ to $60 \mathrm{~min}$ (Figs. $5 \mathrm{~d}$ and 5e). Delayed degradation of EGFR in $U b b$ siRNA-transfected HeLa cells was also observed by immunostaining (Supplementary Fig. 7). At $3 \mathrm{~h}$ after treatment with EGF, significant amounts of EGFR were detected in $U b b$
siRNA-transfected cells, whereas little was observed in control cells (Supplementary Fig. 7).

Interestingly, $U b b$-KD resulted in an increase in stress-inducible proteins such as HSP70 and GRP78, cytosolic and ER proteins, respectively (Fig. 5f). PCR and real-time PCR revealed that the expression of the corresponding mRNAs was also upregulated 
a
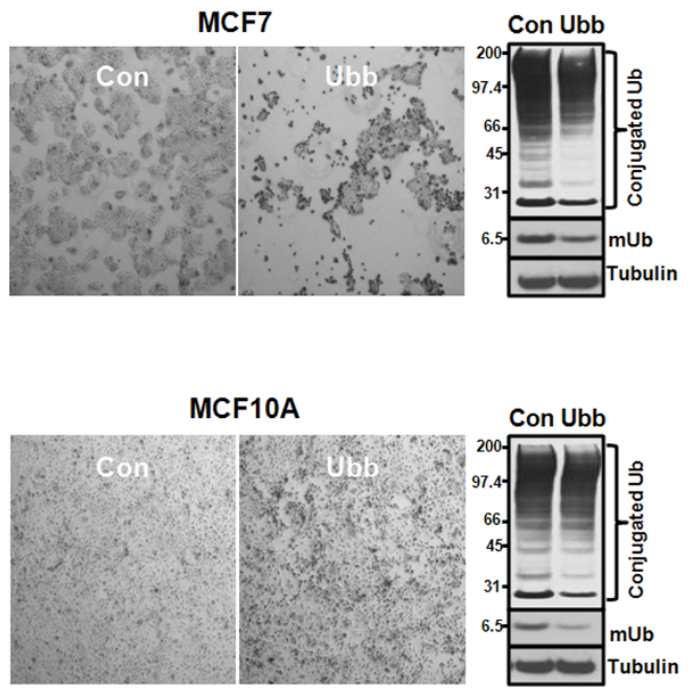

b
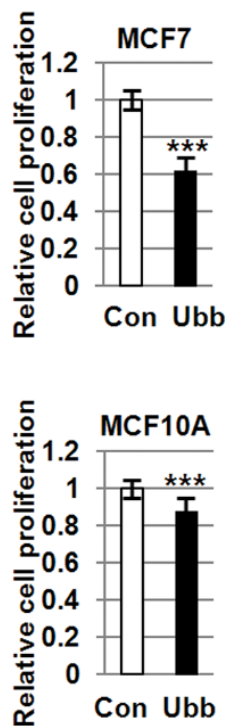

C
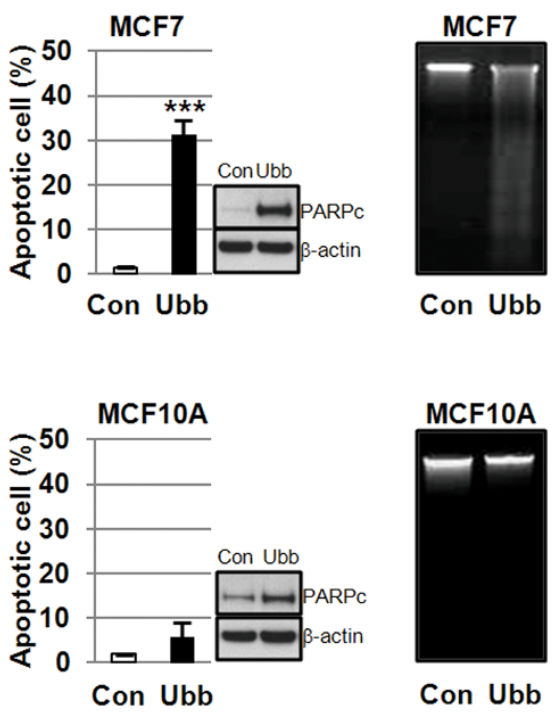

d

Figure $3 \mid U b b$-KD was more cytotoxic to MCF7 than MCF10A cells. (a) MCF7 and MCF10A cells were transfected with control siRNA or Ubb siRNA $(20 \mathrm{nM})$ for $72 \mathrm{~h}$ and then observed by light microscopy. The levels of $\mathrm{Ub}$ in the transfected cells were compared by Western blotting with an anti-Ub antibody; $\alpha$-tubulin was used as a control. (b) Relative cell proliferation was measured by MTT assay $(\mathrm{n}=5)$. (c) The proportion of apoptotic cells at $72 \mathrm{~h}$ was measured by FACS $(n=2)$. The amount of cleaved PARP was also analyzed by Western blot. (d) DNA fragmentation was assessed from isolated genomic DNA. The data are shown as the mean $\pm \mathrm{SD}, * * *, \mathrm{p}<0.001$.

(Figs. $5 \mathrm{~g}$ and $5 \mathrm{~h}$ ), implying that $U b b$-KD results in stress overload in cancer cells.

$\boldsymbol{U} \boldsymbol{b} \boldsymbol{b}$-KD inhibits TNF $\boldsymbol{\alpha}$-induced NF- $\mathbf{B}$ activation. The NF- $\kappa \mathrm{B}$ pathway is the major signaling cascade involved in tumorpromoting inflammation, making it an attractive target for cancer therapy ${ }^{28,29}$. Various cellular stimuli converge on the activation of $N F-\kappa B$, which then induces the expression of a vast array of proteins, including cytokines, growth factors, and anti-apoptotic proteins. To assess the effect of $U b b-\mathrm{KD}$ on NF- $\kappa \mathrm{B}$ activation, we first assessed the $\mathrm{TNF} \alpha$-mediated activation of transcriptional activity in an NF- $\kappa \mathrm{B}$-driven luciferase reporter assay. There was no change in RLA after transfection of $U b b$ siRNA alone. Upon treatment with $50 \mathrm{ng} / \mathrm{ml} \mathrm{TNF} \alpha$ for $2 \mathrm{~h}$, RLA increased $23 \pm 3.7$ fold in control cells but only $6.8 \pm 5$-fold in $U b b$ siRNA-transfected cells, corresponding to $\sim 70 \%$ inhibition (Fig. 6a).

$\mathrm{I} \kappa \mathrm{B} \alpha$ is bound to the NF- $\kappa \mathrm{B}$ dimer $\mathrm{p} 50 / \mathrm{p} 65$ under basal conditions but is rapidly degraded following stimulation, which allows p50/p65 to translocate from the cytoplasm to the nucleus and activate gene expression. Immunostaining of HeLa cells for p65 revealed that p65, which was exclusively located in the cytoplasm, was rapidly translocated into the nucleus in the control cells after treatment with a

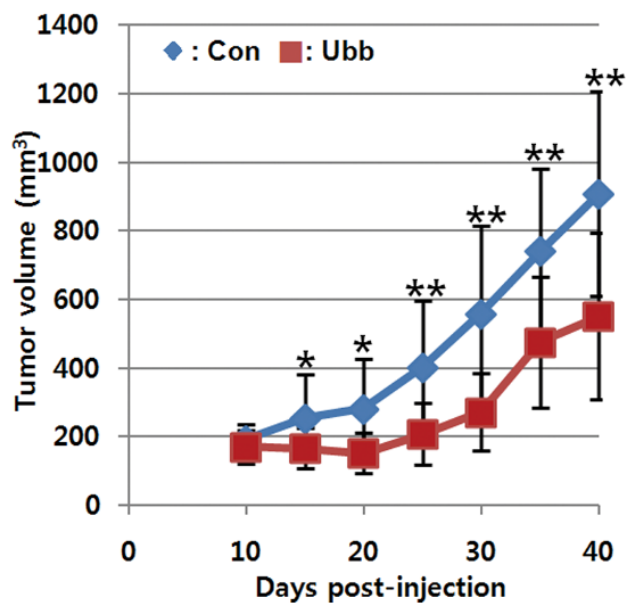

b

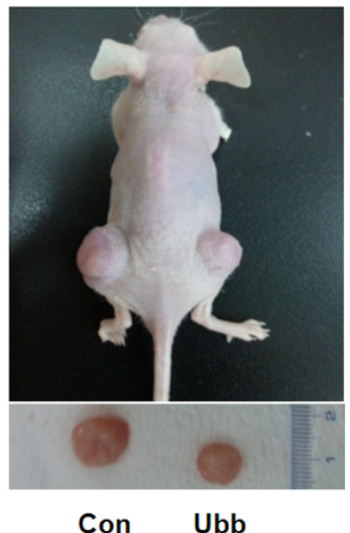

C

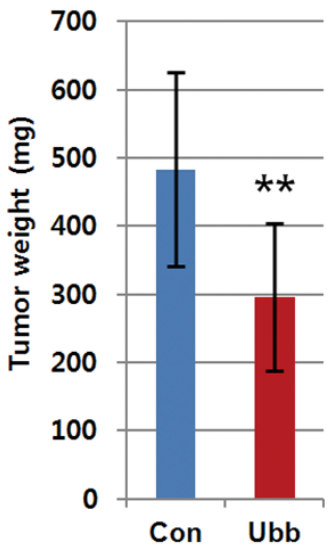

Figure $4 \mid U \boldsymbol{b} b$-KD inhibits tumor cell growth in vivo. (a) PC3 cells $\left(1 \times 10^{7}\right)$ transfected with either control siRNA or Ubb siRNA $(8 \mathrm{nM}$ each) were subcutaneously injected into the left and right flanks of nude mice $(\mathrm{n}=11)$. The size of the tumors was measured every 5 days after injection. (b) The size of the tumors at day 40 after injection was compared. (c) The weight of the tumors was measured after dissection ( $\mathrm{n}=11$ ). The data are shown as the mean $\pm \mathrm{SD},{ }^{*}, \mathrm{p}<0.05 ;{ }^{*}, \mathrm{p}<0.01$. 
a

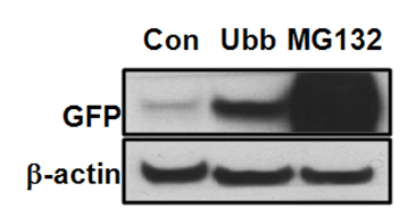

d

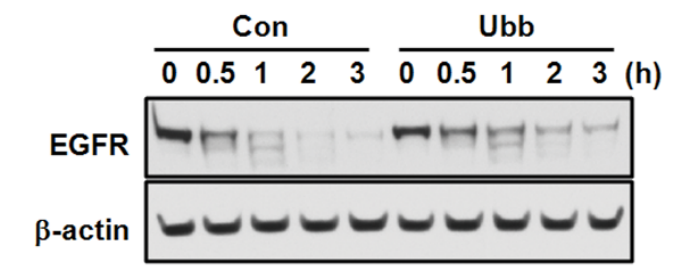

f

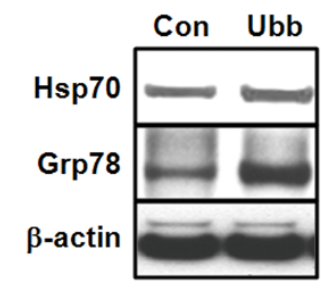

b

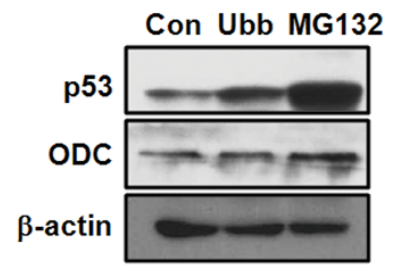

C

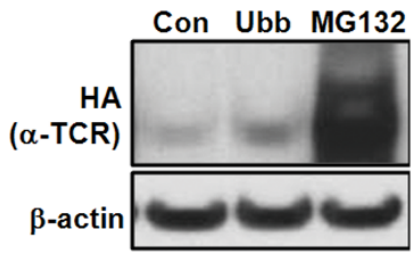

e

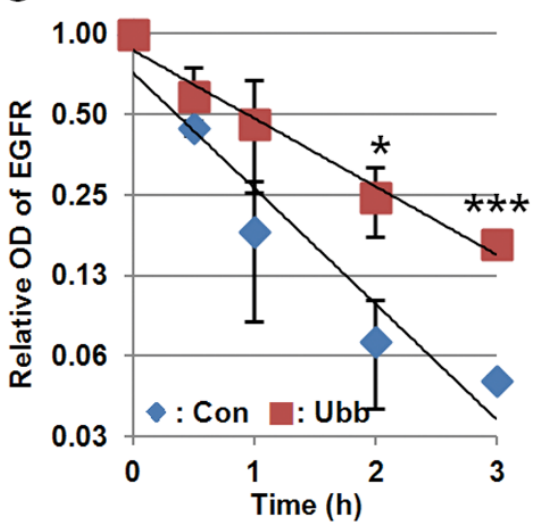

h

g

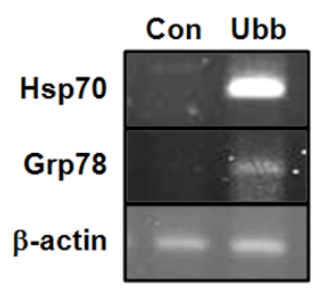

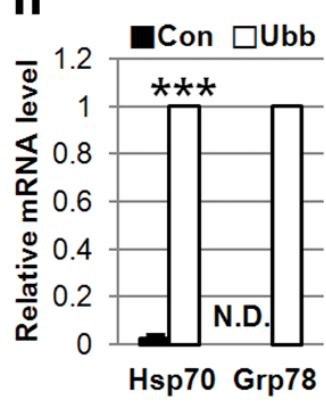

Figure $5 \mid \boldsymbol{U} b \boldsymbol{b}$-KD stabilizes ubiquitination-dependent substrates and induces the expression of stress proteins. (a) SH-SY5Y cells stably expressing GFPu were transfected with $20 \mathrm{nM}$ control or $U b b$ siRNA for $48 \mathrm{~h}$ and then the level of GFPu was assessed by Western blot using antiGFP antibody. $\beta$-actin was used as a control. (b) The levels of p53, ODC, and $\beta$-actin were compared in HepG 2 cells transfected with 20 nM control or Ubb siRNA for $48 \mathrm{~h}$. (c) HeLa cells stably expressing $\alpha$ TCR were transfected with $20 \mathrm{nM}$ control or Ubb siRNA for $72 \mathrm{~h}$, and the level of $\alpha \mathrm{TCR}$ was compared by Western blotting with an anti-HA antibody. MG132 $(10 \mu \mathrm{M})$ was treated for $24 \mathrm{~h}$ as positive control in (a), (b), and (c). (d) HeLa cells were transfected with control siRNA or Ubb siRNA $(20 \mathrm{nM})$ for $48 \mathrm{~h}$ and then treated with EGF (100 ng/ml). The cells were harvested at the indicated times $(0 \mathrm{~h}, 0.5 \mathrm{~h}, 1 \mathrm{~h}, 2 \mathrm{~h}$, and $3 \mathrm{~h}$ ), and the level of EGFR was compared by Western blot. (e) Graph showing optical densities of EGFR from the immunoblot in (d). Values were normalized by $\beta$-actin. (f) HeLa cells were transfected with control siRNA or Ubb siRNA $(20 \mathrm{nM})$ for $72 \mathrm{~h}$, and the levels of HSP70, GRP78, and $\beta$-actin were compared by Western blot. (g and h) Total RNA was isolated from siRNA-transfected HeLa cells after $48 \mathrm{~h}$, and the levels of HSP70 and GRP78 mRNA were compared by PCR (g) and real-time PCR, values were normalized by $\beta$-actin mRNA (h). The data are shown as the mean $\pm \mathrm{SD}(\mathrm{n}=2),{ }^{*}, \mathrm{p}<0.05 ;{ }^{* *}, \mathrm{p}<0.001$; N.D., not detected.

TNF $\alpha$ for 10 min (Fig. 6b). However, Ubb-KD markedly inhibited this translocation of $\mathrm{p} 65$ to the nucleus after the same treatment with TNF $\alpha$ (Fig. 6b). Western blotting of the p65 protein after nuclear/ cytoplasmic fractionation was consistent with the immunostaining results (Fig. 6c). Without $\mathrm{TNF} \alpha$ treatment, the p65 protein was detected only in the cytoplasmic fraction. After treatment with $\mathrm{TNF} \alpha$, more than $50 \%$ of the p65 protein was detected in the nuclear fraction in the control cells, but a substantially lower amount was observed in the Ubb siRNA-transfected cells (Fig. 6c).

$U b b-\mathrm{KD}$ effectively inhibited the degradation of $\mathrm{I} \kappa \mathrm{B} \alpha$ as shown in Fig. $6 \mathrm{D}$, presumably by blocking the ubiquitination of I $\mathrm{B} \alpha$. In addition, we also detected a delay and a decrease in the phosphorylation of $\mathrm{I} \kappa \mathrm{B} \alpha$ (Fig. $6 \mathrm{~d}$ ), suggesting an inhibition of the ubiquitination of upstream molecules in the NF- $\kappa \mathrm{B}$ signaling pathway. Binding of $\mathrm{TNF} \alpha$ to its receptor leads to the recruitment of several signaling molecules; one of these signaling molecules, the receptor-interacting protein kinase (RIP1), has emerged as an important target for polyubiquitination $^{21}$. When we analyzed the ubiquitination level of RIP1 after TNF $\alpha$ treatment, we could clearly observe a delayed and decreased ubiquitination of RIP1 in Ubb siRNA-transfected cells compared with control cells (Fig. 6d). Taken together, these results indicate that $U b b$-KD effectively attenuates TNF $\alpha$-induced NF- $\kappa B$ activation by inhibiting the ubiquitination of upstream signaling molecules as well as I $\mathrm{B} \alpha$.

\section{Discussion}

Given that the level of Ub is elevated in many types of tumors ${ }^{14-19}$, we hypothesized that the level of Ub escalates progressively during a long period of tumorigenesis and that this elevated $\mathrm{Ub}$ level then becomes essential for the survival of cancer cells but not for the viability of normal cells. In this study, we demonstrated that the downregulation of $\mathrm{Ub}$ by $U b b$-KD indeed inhibited the proliferation 
a

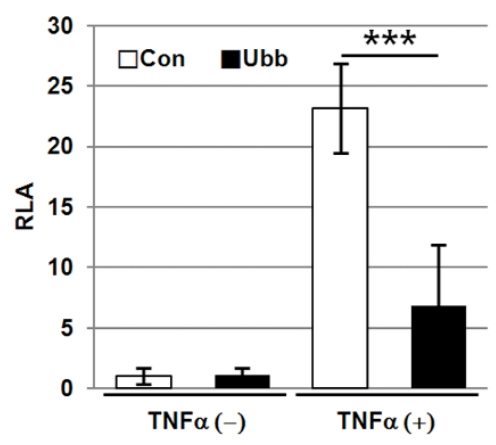

b

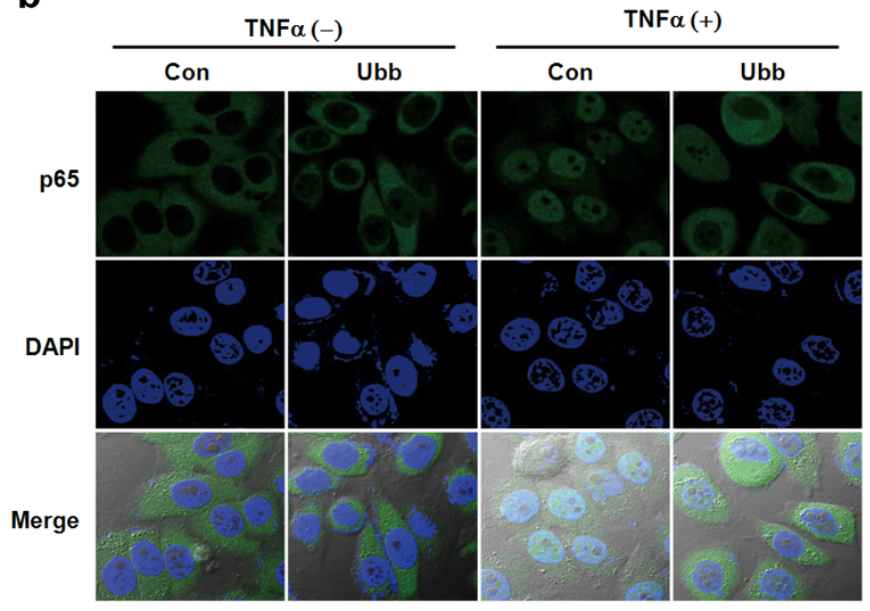

C

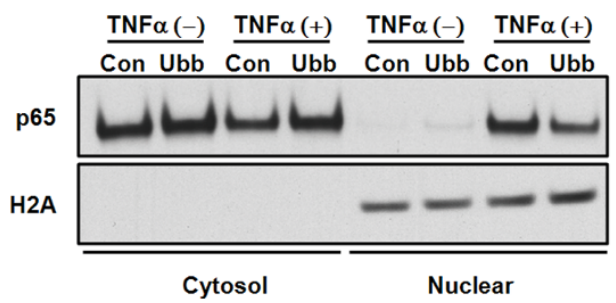

d

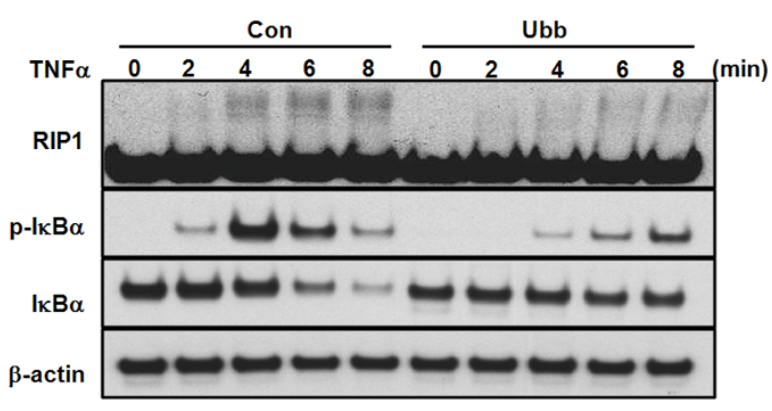

Figure $6 \mid \boldsymbol{U} \boldsymbol{b} \boldsymbol{b}$-KD inhibits TNF $\boldsymbol{\alpha}$-mediated NF-кB activation. (a) HeLa cells were co-transfected with an NF- $\kappa \mathrm{B}(2 \mathrm{x})$ luciferase plasmid (30 ng), HSP70- $\beta$-galactosidase plasmid (30 ng), and control siRNA or Ubb siRNA (20 nM) for $48 \mathrm{~h}$ and then stimulated with $50 \mathrm{ng} / \mathrm{ml}$ TNF $\alpha$ for $2 \mathrm{~h}$. Cells were harvested, and luciferase and $\beta$-galactosidase activity was measured. Luciferase activity was normalized to $\beta$-galactosidase activity. The data are shown as the mean $\pm \mathrm{SD}(\mathrm{n}=6),{ }^{* *}, \mathrm{p}<0.001$. (b) HeLa cells were transfected with control siRNA or Ubb siRNA $(20 \mathrm{nM})$ for $48 \mathrm{~h}$ and then treated with TNF $\alpha$ $(50 \mathrm{ng} / \mathrm{ml})$ for $10 \mathrm{~min}$. Immunostaining of the control $(\mathrm{TNF} \alpha(-))$ and $\mathrm{TNF} \alpha$-treated $(\mathrm{TNF} \alpha(+))$ cells for p65 as described in the Materials and Methods revealed that the majority of the p65 translocated into the nucleus after treatment with TNF $\alpha$; this translocation was substantially inhibited by $U b b$-KD. The nuclei were stained with DAPI. (c) Nuclear and cytosolic fractions were prepared from HeLa cells after the treatment described in (B), and p65 expression was analyzed by Western blot. The amount of p65 in the nuclear fraction was significantly reduced by Ubb-KD. Histone H2A was used as a nuclear marker. (d) HeLa cells were transfected with control siRNA or Ubb siRNA (20 nM) for $48 \mathrm{~h}$ and then treated with $50 \mathrm{ng} / \mathrm{ml} \mathrm{TNF} \alpha$ for the indicated times $(0,2,4,6$, and $8 \mathrm{~min})$. RIP1, phosphorylated $\operatorname{I\kappa B} \alpha(\mathrm{p}-\mathrm{I} \kappa \mathrm{B} \alpha)$, I $\mathrm{K} \mathrm{B} \alpha$, and $\beta$-actin were analyzed by Western blot. Ubiquitinated RIP1 appeared as the higher molecular weight protein in the smear of bands on RIP1 immunoblots.

of several cultured cancer cell lines and was preferentially cytotoxic to MCF7 breast cancer cells over MCF10A normal breast cells. Furthermore, tumor growth of PC3 prostate cancer cells injected subcutaneously into mouse flanks was also inhibited by pretreatment of cancer cells with $U b b$ siRNA. These results strongly support our hypothesis and the anti-cancer potential of the downregulation of $\mathrm{Ub}$ levels through $U b b-\mathrm{KD}$.

Ub exists in a dynamic state between free and conjugated forms in all eukaryotic cells ${ }^{30}$. If the amounts of free and conjugated $\mathrm{Ub}$ are considered to be the cellular supply and demand Ub levels, respectively, the downregulation of free Ub by $U b b$-KD implicates the limited supply of $\mathrm{Ub}$ for continuous as well as signaling-dependent ubiquitination. We also observed that activated $\mathrm{Ub}$, which is linked to the E1 and E2 enzymes through thioester bonds, was similarly decreased when the level of free Ub decreased (Supplementary Fig. 2 ). Regarding this limited supply of $\mathrm{Ub}, U b b$-KD may represent an anti-cancer approach that is similar to that involving the inhibition of E1 enzymes ${ }^{11,31,32}$. However, the anti-cancer effect of $U b b$-KD may be more specific than that of an E1 inhibitor because Ub levels are elevated only in cancer cells and cancer cells are therefore more reliant on the supply of Ub. In this study, we selected $U b b-\mathrm{KD}$ as a tool to downregulate Ub levels because it was reliable with reproducible results. Targeting $U b c$ always resulted in partial degradation of Ubc mRNA and substantial degradation of Rps27a mRNA (data not shown). Studies of $U b b$ and $U b c$ knockout mice ${ }^{33,34}$ also suggested that $U b b-\mathrm{KD}$ might be preferential to $U b c-\mathrm{KD}$, with fewer side effects.

Evasion of apoptosis plays a key role in cancer cell survival, and thus the induction of apoptosis is one of the most important strategies for anti-cancer therapies ${ }^{35,36}$. In this study, $U b b$-KD effectively induced apoptotic cell death in SH-SY5Y cells, PC3 cells, and HepG2 cells, implying that downregulation of Ub blocks the anti-apoptotic capability of cancer cells. Although the mechanism of how the apoptotic signaling pathways are re-operated by $U b b$-KD are not clear, the attenuation of NF- $\kappa \mathrm{B}$ activation by $U b b-\mathrm{KD}$ is likely because NF- $\kappa \mathrm{B}$ is known to promote the expression of various anti-apoptotic proteins $^{28,29}$. Apoptotic cell death could also be induced through the stabilization of the tumor suppressor $\mathrm{p} 53$ by $U b b-\mathrm{KD}$, although it is not the case in p53-null mutant PC3 cells. We also observed that $\mathrm{Ubb}$-KD elicited G2/M arrest and apoptosis consecutively in PC3 cells and HepG2 cells, whereas Ubb-KD led to apoptotic cell death without prior G2/M arrest in SH-SY5Y cells. Taken together, our results suggest that an elevated level of $\mathrm{Ub}$ is essential to allow most cancer cells to evade apoptosis. Ubb-KD thereby induces apoptosis of cancer cells by re-activation of cell type-dependent apoptotic pathways. 
Cancer cells acquire their malignant capabilities through an astounding number of mutations and extensively reprogrammed pathways, which inevitably generate a variety of stresses, including proteotoxic stress ${ }^{22,37}$. Thus, cancer cells must tolerate these increased stresses through stress-supporting systems such as the heat shock response (HSR) and the Ub system to survive; the HSR and the Ub system are thus considered attractive cancer therapeutic targets ${ }^{9,23,38-40}$. The elevated level of Ub in cancer cells is believed to contribute to the reinforcement of this stress-support system through ubiquitination. Therefore, the downregulation of Ub may lead to stress sensitization by weakening the stress-supporting system, as shown by the inhibition of ubiquitination-dependent substrate protein degradation by $U b b-\mathrm{KD}$.

In summary, the downregulation of Ub by $U b b-\mathrm{KD}$ inhibits multiple ubiquitination-mediated pathways and is an effective way to inhibit the proliferation of cancer cells and induce apoptotic cell death, suggesting the downregulation of $\mathrm{Ub}$ as a promising anticancer therapeutic intervention.

\section{Methods}

Cell culture and siRNA transfection. HEK293, HeLa, HepG2, and SH-SY5Y cells were cultured in DMEM (Gibco-BRL, Grand Island, NY, USA) containing 10\% FBS (Hyclone, Logan, UT, USA) and 1\% penicillin/streptomycin (Gibco-BRL). PC3 and MCF7 cells were cultured in RPMI1640 (Gibco-BRL) and Detroit 551 cells were cultured in MEM Alpha (Gibco-BRL) with the same supplements. MCF10A cells were cultured in DMEM-F12 (Gibco-BRL) supplemented with 5\% horse serum (Invitrogen, Carlsbad, CA, USA), $0.5 \mu \mathrm{g} / \mathrm{ml}$ hydrocortisone (SigmaAldrich, St. Louis, MO, USA), $10 \mu \mathrm{g} / \mathrm{ml}$ insulin (Sigma-Aldrich), $20 \mathrm{ng} / \mathrm{ml} \mathrm{EGF}$ (Peprotech, Rocky Hill, NJ, USA), $100 \mathrm{ng} / \mathrm{ml}$ cholera toxin (Sigma-Aldrich), and $1 \%$ penicillin/streptomycin. HeLa cells stably expressing HA- $\alpha$ TCR, which were kindly provided by Dr. Cezary Wójcik (Indiana University) ${ }^{41}$, and SH-SY5Y cells stably expressing unstable GFP $(\mathrm{GFPu})^{42}$ were cultured in DMEM containing $10 \% \mathrm{FBS}, 1 \%$ penicillin/streptomycin, and $0.5 \mu \mathrm{g} / \mathrm{ml}$ G418 (Gibco-BRL). Cells were transfected with siRNA using RNAiMax reagent (Invitrogen) according to the manufacturer's protocol. siRNA against the polyUb gene $U b b$ (Ubb-siRNA), 5'-CCAGCAGAGGCUCAUCUUUUU-3', was prepared by Genolution (Seoul, Korea), and Stealth RNAi Negative Control Med GC (Invitrogen, 12935-300) was used as a control. MG132 (BIOMOL International, Allemagne, Germany) was treated at the final concentration of $10 \mu \mathrm{M}$. zVAD-fmk (Sigma-Aldrich) were added to culture medium after transfection at the final concentration of $20 \mu \mathrm{M}$.

Reverse transcription polymerase chain reaction analysis. Total RNA was prepared using TRI Reagent (Molecular Research Center, Cincinnati, OH, USA) according to the manufacturer's instructions. Briefly, cells were harvested and dissolved in $1 \mathrm{ml}$ Trizol reagent, and then $200 \mu \mathrm{l}$ of chloroform solution was added. After vigorous vortexing, the samples were centrifuged at $12,000 \times g$ at $4{ }^{\circ} \mathrm{C}$ for $15 \mathrm{~min}$, and the upper aqueous phase was transferred to a new tube. An equal volume of isopropanol was added for precipitation. After washing the pellets with $75 \%$ ethanol, the RNA was air-dried and dissolved in nuclease-free water. cDNA was generated from total RNA ( $1 \mu \mathrm{g}$ of each sample) with the oligo (dT) primer (Promega, Madison, WI, USA) and Accupower RT premix (Bioneer, Daejeon, Korea). cDNA was amplified by polymerase chain reaction (PCR) using Taq polymerase (Neurotics, Daejeon, Korea). For quantitative real-time PCR, cDNA was amplified with an $\mathrm{IQ}^{\mathrm{TM}} 5$ real-time PCR detection system (Bio-Rad, Hercules, CA, USA) using $\mathrm{IQ}^{\mathrm{TM}} \mathrm{SYBR}^{\circledR}$ Green Supermix (Bio-Rad). PCR amplification was performed with the following primer sets: Rps27a, 5' -CAGGATAAGGAAGGAATTCCTC- ${ }^{\prime}$ ' and $5^{\prime}$ - CACCACATTCATCAGAAGGG-3'; Uba52, 5' -ACATCCAGAAAGAGTCCACC-3' and $5^{\prime}$-TGAAAGGGACACTTTATTGAGG-3'; $U b b, 5^{\prime}$-GGTGAGCTTGTTTGTGTCCCTGT-3' and $5^{\prime}-$ TCCACCTCAAGGGTGATGGTC-3'; Ubc, 5' -CGCAGCGAGCGTCCTGATCC-3' and $5^{\prime}$-CTAGCTGTGCCACACCCGGC-3', HSP70, 5' -CAAGATCACCATCACCAACG-3' and 5' - GCTCAAACTCGTCCTTCTCG-3'; GRP78, 5' -TAGCGTATGGTGCTGCTGTC- $3^{\prime}$ and $5^{\prime}$ - TTTGTCAGGGGTCTTTCACC- ${ }^{\prime} ; \beta$-actin, $5^{\prime}$-TGTGGCATCCACGAAACTAC-3' and 5'-GGAGCAATGATCTTGATCTTCA-3'

Electrophoresis and Western blotting. Proteins were separated by SDS-PAGE in 4$12 \%$ precast gels (KOMA, Seoul, Korea) and transferred onto nitrocellulose membranes (Bio-Rad) at $25 \mathrm{~V}$ for $2 \mathrm{~h}$. The membranes were blocked with $5 \%$ non-fat milk and incubated with the indicated primary antibody. Prior to blotting with the anti-Ub antibody, membranes were autoclaved at $121^{\circ} \mathrm{C}$ for $10 \mathrm{~min}$. The immunoreactive proteins were visualized with ECL reagent (GE Healthcare/ Amersham Bioscience, Piscataway, NJ, USA). The film was scanned with a GS-800 densitometer (Bio-Rad) and analyzed using QuantityOne software (Bio-Rad). The primary antibodies used in this study were as follows: Ub, GFP, p53, HSP70, GRP78, EGFR, p65, histone $\mathrm{H} 2 \mathrm{~A}$, phospho-I $\mathrm{B} \mathrm{B} \alpha, \mathrm{I} \kappa \mathrm{B} \alpha$, and $\beta$-actin (Santa Cruz Biotechnology); E1 (Abcam, Cambridge, UK); UBE2K/E2-25K (Boston Biochem, Cambridge, USA); hemagglutinin (HA) (Covance, Princeton, NJ, USA); RIP1 (BD biosciences, San Jose, CA, USA); cleaved PARP (Cell Signaling Technology, Beverly, MA, USA); and $\alpha$-tubulin (Lab Frontier, Seoul, Korea). Original blots for cropped images are provided in Supplementary Figure S8.

Non-reduced/reduced two-dimensional electrophoresis (NR/R-2DE). NR/R-2DE was carried out as described previously ${ }^{43}$. Briefly, total protein extracts in SDS sample buffer lacking reducing agent were separated by SDS-PAGE under non-reducing conditions. Each gel lane was excised, incubated with $65 \mathrm{mM} \mathrm{DTT}$ for $15 \mathrm{~min}$, loaded horizontally onto a $4-12 \%$ precast gel, and covered with SDS sample buffer containing 5\% $\beta$-mercaptoethanol. Proteins in the gel were then separated perpendicularly under reducing conditions during the second round of electrophoresis.

Nuclear/cytoplasmic fractionation. Cells were resuspended in buffer A (10 mM Tris- $\mathrm{HCl}$ (pH 7.8), $5 \mathrm{mM} \mathrm{MgCl}, 10 \mathrm{mM} \mathrm{KCl}, 0.3 \mathrm{mM}$ EGTA, $0.3 \mathrm{M}$ sucrose, $10 \mathrm{mM} \beta$-glycerol phosphate, $0.5 \mathrm{mM}$ DTT, $0.5 \%(\mathrm{v} / \mathrm{v}) \mathrm{NP}-40,1 \times$ protease cocktail (Roche Biochemical, Indianapolis, IN, USA)), incubated on ice for $15 \mathrm{~min}$, and centrifuged at $7200 \times g$ at $4^{\circ} \mathrm{C}$ for $10 \mathrm{~min}$. The supernatant was used as the soluble cytoplasmic fraction. The pellet was washed with buffer A and resuspended in SDS buffer with brief sonication. After centrifugation, the supernatant was used as the nuclear fraction.

Assays for cell proliferation, apoptosis, cell cycle distribution, and colony formation. Cells were seeded in 24 -well plates at a density of $4 \times 10^{4}$ cells per well, grown for $24 \mathrm{~h}$, and then transfected with $20 \mathrm{nM}$ control siRNA or $U b b$ siRNA. After $72 \mathrm{~h}$, images of the cells were acquired with a CoolSNAP mono CCD camera (Optronics, Los Angeles, CA, USA), and the relative cell proliferation was determined by MTT assay ${ }^{44}$. Cellular DNA contents were assessed via propidium iodide (PI) staining to determine the percentage of apoptotic cells as well as cell cycle distribution. Briefly, the transfected cells were harvested at the indicated times and fixed in $70 \%$ ethanol overnight. After washing with PBS, the fixed cells were treated with $0.5 \mu \mathrm{g} / \mathrm{ml}$ of DNase-free RNase (Sigma-Aldrich) for $20 \mathrm{~min}$ at RT and stained with $100 \mu \mathrm{g} / \mathrm{ml}$ of PI in $0.1 \mathrm{M}$ sodium citrate buffer $(\mathrm{pH} 7.4)$ at $4^{\circ} \mathrm{C}$ for $30 \mathrm{~min}$. Cells were analyzed by flow cytometry with an EPICS XL-MCL (Beckman Coulter, Fullerton, CA, USA), and cell cycle distribution was determined with the Expo32 program (Beckman Coulter). The sub-G1 population was measured as apoptotic cells. Genomic DNA was also isolated with a G-spin total DNA extraction kit (Intron Biotechnology, Seoul, Korea) according to the manufacturer's protocol, separated by agarose gel electrophoresis, and visualized by ethidium bromide staining. A total of 1,000 cells transfected with $20 \mathrm{nM}$ control or $U b b$ siRNA were seeded in $60 \mathrm{~mm}$ dishes. After 7 days, cells were fixed with methanol and stained with $0.5 \%$ crystal violet.

Tumor growth study in vivo. PC3 cells were transfected with $8 \mathrm{nM}$ control siRNA or $U b b$ siRNA for $12 \mathrm{~h}$. After washing the harvested cells with PBS, $10^{7}$ cells were subcutaneously injected into the left and right flanks of 7-week-old nude mice (athymic BALB/c). Tumor size was measured every fifth day for 40 days on a total of 11 male mice. Tumor volume was calculated using the formula: (length $\times$ width $\left.^{2}\right) / 2$. For this experiment, male athymic BALB/c mice were obtained from Orient Bio (Seoul, Korea) and maintained under pathogen-free conditions in an animal facility at the Gwangju Institute of Science \& Technology (GIST). All the animal experiments were approved by GIST Animal Care and Use committee.

Immunostaining. HeLa cells transfected with $20 \mathrm{nM}$ control siRNA or $U b b$ siRNA were grown on glass cover slips for $48 \mathrm{~h}$. After treatment with $50 \mathrm{ng} / \mathrm{ml} \mathrm{TNF} \alpha$ for $10 \mathrm{~min}$ or with $100 \mathrm{ng} / \mathrm{ml} \mathrm{EGF}$ for $0 \mathrm{~h}, 0.5 \mathrm{~h}$, and $3 \mathrm{~h}$, the cells were fixed in $4 \%$ paraformaldehyde in PBS for 20 min and then permeabilized with $0.2 \%$ Triton X-100 in PBS. After fixation, the cells were washed 3 times with PBS and blocked with $1 \%$ bovine serum albumin for $20 \mathrm{~min}$. The cells were incubated with primary antibody (anti-p65 or anti-EGFR) overnight at $4^{\circ} \mathrm{C}$. The cells were then washed 3 times with PBS, incubated with a $1: 100$ dilution of fluorescein isothiocyanate (FITC)conjugated secondary antibody (Sigma-Aldrich), and then washed 3 times with PBS Nuclei were labeled with DAPI (Invitrogen) in PBS for 5 min at RT. After a final wash in PBS, the cells were mounted onto slides with anti-fade mounting medium (Molecular Probes Inc., Eugene, OR, USA) and analyzed with an FV1000 confocal laser scanning microscope (Olympus Corporation, Tokyo, Japan). Images were obtained with Fluoview software (Olympus Corporation).

NF-кB-driven luciferase activity assay. A NF- $\kappa \mathrm{B}(2 \mathrm{x})$-luciferase reporter plasmid, which was kindly provided by Frank Mercurio (Signal Pharmaceuticals, San Diego, CA, USA), was co-transfected into HeLa cells with control siRNA or Ubb siRNA using Lipofectamine 2000 (Invitrogen). A heat shock protein 70 (HSP70)- $\beta$ galactosidase reporter plasmid, which was kindly provided by Robert Modlin (University of California, Los Angeles, CA, USA), was also co-transfected as an internal control. After transfection for $48 \mathrm{~h}$, HeLa cells were treated with TNF $\alpha$ $(50 \mathrm{ng} / \mathrm{ml})$ before assaying luciferase activity. Luciferase and $\beta$-galactosidase enzyme activities were determined with the Luciferase Assay System and $\beta$-galactosidase Enzyme System (Promega) according to the manufacturer's instructions, and luciferase activity was normalized to $\beta$-galactosidase activity to obtain the relative luciferase activity (RLA). 
1. Hershko, A. \& Ciechanover, A. The ubiquitin system. Annu. Rev. Biochem. 67, 425-479 (1998).

2. Pickart, C. M. Mechanisms underlying ubiquitination. Annu. Rev. Biochem. 70, 503-533 (2001).

3. Weissman, A. M. Themes and variations on ubiquitylation. Nat. Rev. Mol. Cell Biol. 2, 169-178 (2001)

4. Kulathu, Y. \& Komander, D. Atypical ubiquitylation - the unexplored world of polyubiquitin beyond Lys48 and Lys63 linkages. Nat. Rev. Mol. Cell Biol. 13, 508-523 (2012).

5. Husnjak, K. \& Dikic, I. Ubiquitin-binding proteins: decoders of ubiquitinmediated cellular functions. Annu. Rev. Biochem. 81, 291-322 (2012).

6. Hicke, L., Schubert, H. L. \& Hill, C. P. Ubiquitin-binding domains. Nat. Rev. Mol. Cell Biol. 6, 610-621 (2005).

7. Reyes-Turcu, F. E., Ventii, K. H. \& Wilkinson, K. D. Regulation and cellular roles of ubiquitin-specific deubiquitinating enzymes. Annu. Rev. Biochem. 78, 363-397 (2009)

8. Ciechanover, A. \& Schwartz, A. L. The ubiquitin system: pathogenesis of human diseases and drug targeting. Biochim. Biophys. Acta 1695, 3-17 (2004).

9. Hoeller, D. \& Dikic, I. Targeting the ubiquitin system in cancer therapy. Nature 458, 438-444 (2009).

10. Bedford, L., Lowe, J., Dick, L. R., Mayer, R. J. \& Brownell, J. E. Ubiquitin-like protein conjugation and the ubiquitin-proteasome system as drug targets. Nat. Rev. Drug Discov. 10, 29-46 (2011).

11. Yang, Y. et al. Inhibitors of ubiquitin-activating enzyme (E1), a new class of potential cancer therapeutics. Cancer Res. 67, 9472-9481 (2007).

12. Verma, R. et al. Ubistatins inhibit proteasome-dependent degradation by binding the ubiquitin chain. Science 306, 117-120 (2004).

13. Fraile, J. M., Quesada, V., Rodriguez, D., Freije, J. M. \& Lopez-Otin, C. Deubiquitinases in cancer: new functions and therapeutic options. Oncogene 31, 2373-2388 (2012).

14. Ishibashi, Y. et al. Ubiquitin immunoreactivity in human malignant tumours. $\mathrm{Br}$. J. Cancer 63, 320-322 (1991).

15. Kanayama, H. et al. Changes in expressions of proteasome and ubiquitin genes in human renal cancer cells. Cancer Res. 51, 6677-6685 (1991).

16. Ishibashi, Y. et al. Quantitative analysis of free ubiquitin and multi-ubiquitin chain in colorectal cancer. Cancer Lett. 211, 111-117 (2004).

17. Morelva Tde, M. \& Antonio, L. B. Immunohistochemical expression of ubiquitin and telomerase in cervical cancer. Virchows Arch. 455, 235-243 (2009).

18. Finch, J. S. et al. Overexpression of three ubiquitin genes in mouse epidermal tumors is associated with enhanced cellular proliferation and stress. Cell Growth Differ. 3, 269-278 (1992).

19. Osada, T. et al. Increased ubiquitin immunoreactivity in hepatocellular carcinomas and precancerous lesions of the liver. J. Hepatol. 26, 1266-1273 (1997).

20. Turner, G. C. \& Varshavsky, A. Detecting and measuring cotranslational protein degradation in vivo. Science 289, 2117-2120 (2000).

21. Bhoj, V. G. \& Chen, Z. J. Ubiquitylation in innate and adaptive immunity. Nature 458, 430-437 (2009).

22. Luo, J., Solimini, N. L. \& Elledge, S. J. Principles of cancer therapy: oncogene and non-oncogene addiction. Cell 136, 823-837 (2009).

23. Neznanov, N., Komarov, A. P., Neznanova, L., Stanhope-Baker, P. \& Gudkov, A. V. Proteotoxic stress targeted therapy (PSTT): induction of protein misfolding enhances the antitumor effect of the proteasome inhibitor bortezomib. Oncotarget 2, 209-221 (2011).

24. Fornace Jr., A. J., Alamo Jr., I., Hollander, M. C. \& Lamoreaux, E. Ubiquitin mRNA is a major stress-induced transcript in mammalian cells. Nucleic Acids Res. 17, 1215-1230 (1989).

25. Finley, D., Ozkaynak, E. \& Varshavsky, A. The yeast polyubiquitin gene is essential for resistance to high temperatures, starvation, and other stresses. Cell $\mathbf{4 8}$, 1035-1046 (1987).

26. Bence, N. F., Sampat, R. M. \& Kopito, R. R. Impairment of the ubiquitinproteasome system by protein aggregation. Science 292, 1552-1555 (2001)

27. Mukhopadhyay, D. \& Riezman, H. Proteasome-independent functions of ubiquitin in endocytosis and signaling. Science 315, 201-205 (2007).

28. Karin, M. Nuclear factor-kappaB in cancer development and progression. Nature 441, 431-436 (2006)
29. Nakanishi, C. \& Toi, M. Nuclear factor-kappaB inhibitors as sensitizers to anticancer drugs. Nat. Rev. Cancer 5, 297-309 (2005).

30. Kimura, Y. \& Tanaka, K. Regulatory mechanisms involved in the control of ubiquitin homeostasis. J. Biochem. 147, 793-798 (2010)

31. Kitagaki, J. et al. Nitric oxide prodrug JS-K inhibits ubiquitin E1 and kills tumor cells retaining wild-type p53. Oncogene 28, 619-624 (2009).

32. Xu, G. W. et al. The ubiquitin-activating enzyme E1 as a therapeutic target for the treatment of leukemia and multiple myeloma. Blood 115, 2251-2259 (2010).

33. Ryu, K. Y. et al. The mouse polyubiquitin gene UbC is essential for fetal liver development, cell-cycle progression and stress tolerance. Embo J. 26, 2693-2706 (2007).

34. Ryu, K. Y., Garza, J. C., Lu, X. Y., Barsh, G. S. \& Kopito, R. R. Hypothalamic neurodegeneration and adult-onset obesity in mice lacking the Ubb polyubiquitin gene. Proc. Natl. Acad. Sci. U S A 105, 4016-4021 (2008).

35. Ghobrial, I. M., Witzig, T. E. \& Adjei, A. A. Targeting apoptosis pathways in cancer therapy. CA Cancer J. Clin. 55, 178-194 (2005).

36. Fesik, S. W. Promoting apoptosis as a strategy for cancer drug discovery. Nat. Rev. Cancer 5, 876-885 (2005).

37. Hanahan, D. \& Weinberg, R. A. Hallmarks of cancer: the next generation. Cell 144, 646-674 (2011).

38. Lindquist, S. The heat-shock response. Annu. Rev. Biochem. 55, 1151-1191 (1986)

39. Sherman, M. Y. Proteotoxic stress targeted therapy (PSTT). Oncotarget 2 356-357 (2011).

40. Maloney, A. \& Workman, P. HSP90 as a new therapeutic target for cancer therapy: the story unfolds. Expert Opin. Biol. Ther. 2, 3-24 (2002).

41. Wojcik, C. et al. Valosin-containing protein (p97) is a regulator of endoplasmic reticulum stress and of the degradation of $\mathrm{N}$-end rule and ubiquitin-fusion degradation pathway substrates in mammalian cells. Mol. Biol. Cell 17, 4606-4618 (2006).

42. Lee, E. K., Park, Y. W., Shin, D. Y., Mook-Jung, I. \& Yoo, Y. J. Cytosolic amyloidbeta peptide 42 escaping from degradation induces cell death. Biochem. Biophys. Res. Commun. 344, 471-477 (2006).

43. Shin, D. Y., Lee, H., Park, E. S. \& Yoo, Y. J. Assembly of different length of polyubiquitins on the catalytic cysteine of E2 enzymes without E3 ligase; a novel application of non-reduced/reduced 2-dimensional electrophoresis. FEBS Lett. 585, 3959-3963 (2011).

44. Carmichael, J., DeGraff, W. G., Gazdar, A. F., Minna, J. D. \& Mitchell, J. B. Evaluation of a tetrazolium-based semiautomated colorimetric assay: assessment of radiosensitivity. Cancer Res. 47, 943-946 (1987).

\section{Acknowledgements}

This work was supported by a grant for the Study of Ubiquitome Functions from the Korea Ministry of Education, Science \& Technology (KMEST) and by a "Systems Biology Infrastructure Establishment Grant” provided by the GIST.

\section{Author contributions}

Y.J.Y. conceived and designed the study. C.O. and S.P. performed the experiments. E.K.L. helped to do the experiments. Y.J.Y. and C.O. wrote the paper.

\section{Additional information}

Supplementary information accompanies this paper at http://www.nature.com/ scientificreports

Competing financial interests: The authors declare no competing financial interests.

How to cite this article: Oh, C., Park, S., Lee, E.K. \& Yoo, Y.J. Downregulation of ubiquitin level via knockdown of polyubiquitin gene $U b b$ as potential cancer therapeutic intervention. Sci. Rep. 3, 2623; DOI:10.1038/srep02623 (2013).

cc) (i) $\Theta$ This work is licensed under a Creative Commons

NonCommercial-NoDerivs 3.0 Unported license. To view a copy of this license, visit http://creativecommons.org/licenses/by-nc-nd/3.0 